\title{
MIR506 Pre-miRNA
}

National Cancer Institute

\section{Source}

National Cancer Institute. MIR506 Pre-miRNA. NCI Thesaurus. Code C134705.

MIR506 pre-miRNA (124 bases) is encoded by the human MIR506 gene. This

oligoribonucleotide may be involved in the post-transcriptional regulation of gene expression. 